Doutor em História Social pela Pontifícia Universidade Católica de São Paulo (2001), com bolsa CNPQ e bolsa sanduiche CAPES (1998-99) na Université Lumiere (Lyon 2/ França). Professor Adjunto no Departamento de História, ligado aos programas de Poss-Graduação em Historia e em Letras da Pontifícia Pós-doutorado (Estágio Sênior com do Sul(PUCRS). História Cultural e Social da Arte na Université Paris 1 Panthéon - Sorbonne (2013-2014) sob supervisão de Michel Poivert.

http://orcid.org/0000-0003-1498-8155

E-mail: monteiro@pucrs.br

2 Doutor em História e Civilização (1997) na École des Hautes França. Professor da Pontificia Universidade Carólica do Chile (PUC- Chile) - Instituto de Estética. DEA Master Europeu Historia Cultural Latino-american (1994) EHESS, Paris, França. Autor de diversos livros, entre eles: Multitudes en Sombras (Ocho Livros, 2008) golpe Estetico. Dictadura Militar em Chile 1973-1989

E-mail: gleivaq@gmail.com

3 Mestre em Letras pela Universidade Federal de Pelotas (UFPel) e doutorando em Letras - Teoria da Literatura - pela Pontificia Universidade Católica do Rio Grande do Sul (PUCRS). Bolsista CNPq. https://orcid.org/0000-0002-4100-08 E-mail: ivens_matozo@hotmail.com

Recebido em: 4/5/2019 Aprovado em: 5/7/2019.

Publicado em: 16/12/2019.

Endereço:

. 6681 Prédio 8 sala 402.06 - Partenon -

Porto Alegre, RS, CEP. 90619-900. \section{a expansão de um novo campo de pesquisas no século XXI \\ Literatura e Fotografia:}

Literature and Photography: on the broadening scope of a new research field in the $21^{\text {st }}$ century

Charles Monteiro 1

Pontifícia Universidade Católica do Rio Grande do Sul, Escola de Humanidades, Programa de Pós-Graduação em História e Letras, Porto Alegre, RS, Brasil

Gonzalo Leiva Quijada²

Pontifícia Universidade Católica do Chile, Instituto de Estética, Santiago, Chile.

Ívens Matozo Silva ${ }^{3}$

Pontifícia Universidade Católica do Rio Grande do Sul, Escola de Humanidades, Programa de Pós-Graduação em Letras, Porto Alegre, RS, Brasil .

Gala-se de Literatura Comparada quando se lê a Literatura à luz da História da Arte. Contudo, o termo também engloba - os estudos que se debruçam sobre a inter-relação estabelecida entre o texto e a imagem, os quais se propõem a ser um estudo comparativo em diálogo com os chamados Estudos Culturais. Na era em que a tecnologia das imagens está em plena expansão, não é de se admirar que os teóricos, críticos e historiadores da literatura se interessem pela cultura visual, a qual sempre esteve lado a lado com o universo das letras.

Nesse sentido, é legitimo que se considere a fotografia como um lugar de debate literário. Nas obras literárias, ela aparece ora em meio ao texto, confirmando ou completando o sentido das palavras, ora colocando em evidência as palavras, ora posicionando-a em oposição ou tensão com as palavras. Seja como for, a fotografia caracteriza-se pelo envolvimento de um discurso público e privado que circunda as imagens. 
Até os anos 1980, a crítica literária, em seu conjunto, ignorou a fotografia, mesmo admitindo que alguns escritores tenham se interessado por ela. Esse é o caso, por exemplo, de Lewis Carroll (que, além de escritor, foi fotógrafo amador) ou de Victor Hugo e Virginia Wolf (os quais praticavam a arte fotográfica somente em ambiente familiar). Nesse contexto, é notório que, tanto as obras literárias, quanto a fotografia, pareciam, naquela época, seguir linhas paralelas, sem jamais se tocarem, sem interações ou influências mútuas (MONTIER, 2008, p. 7).

Todavia, o texto fundador de Baudelaire, "Le public moderne et la photographie", coloca, de maneira clara, a distinção e o distanciamento entre a Literatura e a Fotografia. Enquanto a primeira estaria ao lado da arte, a segunda situar-se-ia ao lado da indústria e da ciência. Demasiadamente ligada ao atual, a fotografia não poderia representar a modernidade, visto que a literatura, ao transitar entre o clássico e o atual (a moda), seria uma apresentação moderna. Assim, o fotografar poderia, no máximo, almejar ser uma "simples serva da arte", desempenhando um papel de esboço ou arquivamento das obras para a posteridade.

Indo na contramão do pensamento que assegurava a falta de interação entre as duas áreas, Jérôme Thélot (2004) traz importantes reflexões. Segundo ele, tanto a Literatura quanto a fotografia são duas formas de arte que se influenciaram mutuamente. Nessa perspectiva, pode-se interpretar que a literatura contribuiu para a invenção da ideia de fotografia, modelando-a, construindo o seu imaginário e desenvolvendo a sua teoria através de obras de ficção. Por conseguinte, percebe-se que, reciprocamente, a fotografia renovou a literatura.

Nesse sentido, é possível compreender a importância da publicação do livro Câmera Clara, de Roland Barthes, em 1980, para a renovação das pesquisas sobre as duas áreas. De acordo com François Brunet (2004, p. 64), essa obra se destaca por conseguir inaugurar uma tradição crítica sobre a fotografia e pode ser lida, simultaneamente, como um texto teórico sobre a fotografia, um fotoensaio, um álbum pessoal ou até mesmo como um autobiográfico roman-photo.

Barthes (2015) assinala as três práticas ligadas ao fotografar: a do fazer, a do suportar e a do olhar. 0 fazer é representado pelo Operator (fotógrafo). 0 olhar é apresentado pelo Spectator (leitor e observador), posição assumida pelo autor. $O$ suportar relaciona-se pela ligação entre a imagem e o seu referente, o qual aparece na fotografia como o Spectrum, ou fantasma, em sua condição inevitável de retorno do morto. Ao se posicionar como Spectator para o desenvolvimento de sua análise, Barthes se afasta da fotografia segundo a perspectiva do fotógrafo (Operator). Sua famosa distinção entre o Studium e o Punctum foram amplamente debatidas. 0 termo studium vem do verbo studare, que é um estudo do mundo: tudo aquilo que não tem pungência. Já o punctum, por sua vez, vem do verbo latino pungere, significando "picar", "furar", "perfurar". É interessante frisar que é possível encontrar os dois termos em uma mesma foto. 0 studium é a fotografia que vem informar e comunicar o sujeito observador (Spectador) - a fotografia como um campo de estudo - aquilo que se apresenta naturalmente ao espírito. 0 conceito de punctum advém da própria imagem, tornando-a transparente ao olhar. 0 termo referese, dessa forma, a algo que cala e que fascina. Dito em outros termos, tem-se aqui o campo do indizível da imagem, aquilo afeta o corpo do observador.

Na mesma linha de raciocínio, a pesquisadora Natália Brizuela (2009), ao discorrer sobre essa questão, na introdução do seu livro Depois da Fotografia. Uma literatura fora de si, afirma que:

Aquilo que se vê na imagem existe (deste exato modo) tão só na imagem. De todos os meios através dos quais a arte adquire presença, a fotografia é o que contém essa heterogeneidade, essa convivência de polos opostos. A fotografia sempre, e ao mesmo tempo, é arte e não arte. 0 dispositivo fotográfico permite algo contraditório ou em tensão: aproximar-se e afastar-se da realidade. É um espelho que reflete algo que não existe fora do espelho, algo assim como um espelho autorreferencial, autoreflexivo. É mimético. Mas o é falsamente, ou mentirosamente. Porque toda a fotografia é também, antes de tudo, uma operação de montagem - corte dissecção, reorganização para decompor a realidade - e por isso produção de uma heterogeneidade que só pode ser entendida como estética e não mimética (BRIZUELA, 2009, p. 19).

O panorama do campo dos estudos sobre a Literatura e a Fotografia se altera profundamente a partir dos anos 1990. Parte disso deve-se à realização de uma série de seminários que passaram a problematizar as relações entre as duas áreas, bem como a publicação de várias obras, dentre elas Photography and Literature (1992), Fiction in the age of photography (1999), La Littérature à l' ère de la photographie (2004), Les inventions littéraires de la photographie (2004), Littérature et Photographie (2009) entre outras. Vale ressaltar, nesse momento, que 
o conjunto desses livros fizeram avançar consideravelmente a pesquisa sobre a invenção da fotografia, assim como a sua apropriação por vários artistas, escritores e escritoras pertencentes ao cânone da história da literatura dos séculos XIX e XX.

Segundo Jean-Pierre Montier (2009, p. 9), a fotografia possui um valor semiótico particular. De acordo com o estudioso, ela tem como principais características uma participação no questionamento e na colocação em perspectiva do estatuto da obra de arte. Aliás, para Montier, a fotografia igualmente traz à tona noções relativas à identidade, ao retrato, à paisagem e, de forma mais geral, à própria ideia de mimeses na literatura.

Philippe Ortel (2002) afirma que ocorreu uma verdadeira "revolução invisível" a partir da invenção da fotografia. Através da instauração de um visível/reprodutível, próprio da era industrial, a qual se encontra ligada a novos dispositivos óticos e às novas técnicas, ter-se-ia engendrado uma transformação do conceito de ponto de vista e uma pluralidade do uso de distintas vozes narrativas. Isso ocorreu, consoante o autor, bem antes da invenção do olhar-câmera, que foi diretamente influenciado pela emergência de uma forma de ubiquidade ou complexidade do ponto de visão, própria das imagens fotográficas. Na mesma esteira de pensamento, encontramos as reflexões teóricas prestadas por François Brunet em seu livro Photography and Literature (2009). De acordo com o crítico, há uma coincidência não apenas entre a invenção da fotografia, mas também entre a sua percepção como uma técnica e com o conceito de verdade visual baseada em uma verdade social, a qual surgiu com o advento pós-romântico da literatura, cuja representação era vista como a expressão cultural legítima da criatividade individual.

Nessa perspectiva, a invenção da fotografia, no século XIX, veio a alterar as posições estabelecidas no campo das artes. A literatura era, então, uma arte legitimada. Ao seu lado, a figura do autor, do romancista e a do poeta conseguiram alcançar legitimidade cultural e social. Por outro lado, a fotografia foi considerada uma técnica, demasiadamente próxima à nova sociedade industrial e as suas demandas de reprodutibilidade de baixo custo. A foto era, portanto, uma espécie de arte democratizada, a qual colocava a imagem ao acesso às massas. Porém, artistas e escritores se faziam fotografar e estampavam as suas imagens nas páginas dos jornais, das revistas e na contracapa dos seus livros, para que o seu público leitor os conhecesse. Isso teria colaborado, de maneira decisiva, para a construção da moderna figura do autor.
Montier (2008) explora os possíveis impactos deste novo olhar sobre o fotográfico e sobre o "triunfo das coisas vistas", tendo como ponto de partida uma expressão do escritor Victor Hugo, a mutação da concepção de diário íntimo. Seu texto apresenta uma série de reflexões, bem como uma apurada busca por respostas. Assim, Montier é guiado pelos seguintes questionamentos: seria possível afirmar que a fotografia não teria tido impacto sobre a literatura de viagem, considerando não só a percepção dos lugares e dos países distantes (exóticos), como também a representação do "Outro" em uma época de conquistas e explorações coloniais? A técnica do instantâneo fotográfico e a possibilidade da decomposição do movimento (inventada por Eadweard James Muybridge e Étienne-Jules Marey) não teriam fornecido novos modelos de representação do tempo para a literatura? Afora isso, o autor questiona o resultado da colaboração entre um escritor e um fotógrafo: um livro ilustrado, ou simplesmente acompanhado por fotografias, não teria tido repercussões na evolução do objeto livro?

Em Fiction in the Age of Photography: The Legacy of British Realism, Nancy Armstrong (1999) apresenta um fascinante olhar sobre a ficção vitoriana. Mais precisamente, ela analisa como a popularidade sem precedentes da fotografia afetou a obra de grandes escritores. Escolhendo romances vitorianos clássicos, Armstrong examina as obras de autores como Charles Dickens, Emily Brönte e Oscar Wilde. Enquanto traça o desenvolvimento do realismo, ela discute as poderosas pistas visuais que começaram a gerar enredos e a determinar como os personagens se relacionavam. Tanto através de comentários sociais, quanto da crítica literária, o livro de Armstrong desvela uma sociedade obcecada pela câmera e sobrecarregada com o que a autora denomina de "visualidade de massa".

As revistas ilustradas da virada do século XIX para o XX propuseram um diálogo intertextual que se ampliou com as vanguardas (Georges Bataille publicou Documents; Andre Breton dirigiu Minotaure), alimentando, dessa forma, um novo terreno para a criação, onde a palavra e a imagem estavam entrelaçadas, conformando, assim, novos imaginários culturais. Se, no início do século XX, o surrealismo promoveu a fotografia ao campo da arte através de uma ampla utilização em revistas e em livros; nos anos 1960, com a Arte Conceitual, no contexto de uma desmaterialização do objeto artístico, a fotografia se equipara a outros meios de expressão artística. No século XXI, a crise da narrativa é acompanhada por uma abertura ao diálogo entre o texto e a imagem. 0 próprio formato do livro passa a ser questionado e surgem novos meios e suportes para 
a expressão escrita e para a leitura, com possibilidades inovadoras e criativas no âmbito do mundo digital e mediático. Tais processos enunciam novos paradigmas para a criação e para a interpretação desses "textos híbridos", os quais entrelaçam palavra e imagem no campo da literatura e das artes.

Na proposição de Montier (2008), a fotolitetatura poderia fornecer um ângulo de aproximação privilegiada para se pensar as relações entre texto-imagem. $\mathrm{Na}$ emergência de um mundo moderno, a fotografia seria simultaneamente um fator, um catalizador e um analisador privilegiado. Seria um fator no sentido de que não há invenções humanas que não surjam de uma demanda social, econômica, política e cultural. Se, para Marshall McLuhan, a invenção da imprensa produz o "homem tipográfico", a invenção e a disseminação da fotografia faria surgir o "homem fotográfico". No que tange ao caráter Catalizador, Montier assinala a função de provocar mudanças importantes no domínio da estética e da ética. Ela se opôs à pintura e à literatura, que defendiam posições e valores verticais e hierárquicos em uma sociedade aristocrática. Já a fotografia, por seu turno, funcionaria dentro de uma lógica de horizontalidade, porquanto iria ao encontro das características que produziriam o homem democrático (dessacralização, igualdade, uniformização). Por fim, o caráter Analisador, segundo o autor, constituiria uma ferramenta essencial para a compreensão do próprio fenômeno da modernidade, bem como seus desdobramentos no plano das artes e da literatura em particular.

François Soulages, em Estética da fotografia - Perda e permanência (2010), na terceira parte do livro - denominada "A arte fotográfica" - afirma que devemos ter em mente que uma coisa só adquire sentido em função das relações que ela estabelece com as outras. Então, a partir disso, o crítico estuda as conexões que a arte fotográfica mantém com a literatura, refletindo, assim, sobre uma estética da cocriação.

Nas relações entre a fotografia e a literatura, essa cocriação resultaria em uma união entre fotos e textos dentro de uma obra literária. Isso pode ser realizado por meio de três maneiras: pela combinação de fotos e textos que não foram concebidos para serem contemplados em conjunto; pelo ato de um fotógrafo conseguir criar a partir de um texto, ou de um escritor desenvolver seu trabalho a partir de fotos; e, por fim, uma terceira maneira, a mais interessante, segundo o autor, através de um procedimento artístico que não se acrescenta ao outro, mas que nasce do outro. Nesse sentido, nas palavras do estudioso: "a escrita não foi acrescentada à fotografia; nasceu dela e, por um mesmo movimento, revelou, no sentido forte, a fotografia, dando-lhe toda a sua dimensão" (SOULAGE, 2010).

Para Natalia Brizuela (2009), a literatura vindoura, que chamamos de "contemporânea", situar-se-ia em uma fronteira entre a literatura e as outras artes, bem como em uma zona porosa, de contato, contaminação e de metamorfose. Desse modo, tanto a literatura se transforma, quanto as demais artes são modificadas na literatura. Entre as muitas expansões da arte literária estaria a sua passagem para o campo fotográfico, produzindo, dessa forma, diferentes resultados. 0 que não se daria apenas pela inclusão de imagens fotográficas em obras literárias, mas como um:

paradigma de uma nova síntese e de uma nova literatura utilizando certas características do dispositivo fotográfico - como a indexicalidade, 0 corte, o ponto de vista, o pôr em cena, a dupla temporalidade, o caráter documental, sua função mnemônica, o ser uma mensagem sem código (BRIZUELA, 2009, p. 31).

A fotografia narrativa tentaria estabelecer um novo tipo de meio alternativo à palavra escrita, e que, talvez, seja a forma como serão concebidos os livros no futuro. Para Mario Bellatin (2001): "a fotografia é o veículo do deslocamento, é o que permite a produção de uma literatura marcada pela transferência e pela indiferenciação, é o meio que leva a literatura para fora de si, para fora de seu próprio meio" (BELLATIN, 2001, p. 16).

Em meio à multiplicidade de abordagens sobre as relações entre as duas formas artísticas e as suas intersecções com outras linguagens, o dossiê Literatura e Fotografia propõem uma reflexão teórica e crítica sobre as narrativas que ultrapassam uma concepção tradicional, problematizando trânsitos entre a palavra e a imagem, bem como a subversão do formato livro, abordando experimentações que proponham um diálogo entre as artes. Os textos presentes buscam refletir sobre o processo de "contaminação" e também sobre os "deslocamentos" da arte fotográfica na literatura, que se manifesta não apenas através da inclusão de fotografias em obras literárias, mas também pela influência da estética da arte fotográfica na estética da arte literária, seja pela apropriação de certas características do fotográfico (como dispositivo, como modo de olhar e como uma linguagem), seja através da discussão de obras literárias, de fotolivros e de textos teóricos. 
Desde 2011, na Pontifícia Universidade Católica do Rio Grande do Sul, vem sendo oferecido o "Seminário Literatura e Fotografia" no quadro do Programa de Pós-Graduação em Letras (Escrita Criativa). Nele, foi possível observar a escassez da bibliografia em língua portuguesa, frente ao conjunto de obras existentes em língua francesa e inglesa. Com uma perspectiva muitas vezes eurocêntrica, livros como Depois da Fotografia (2009), de Natália Brizuela, Fotografia \& Poesia (2017), de Adolfo Montejo Navas, e a publicação organizada por Dan Russek, denominada Textual Exposures: Photography in Twentieth Century Latin American Narrative Fiction (2015) vieram a ampliar o assunto ao tratar de autores e artistas latino-americanos.

Porém, já existiam alguns artigos, em língua portuguesa, publicados em revistas acadêmicas e anais de congressos sobre o tema Literatura e Fotografia. Nos últimos anos, verificou-se um crescente interesse pelo tema, o qual pode ser constatado na produção de dissertações e teses nos Programas de Pós-Graduação em Letras no Brasil e no exterior. A revista Aletria, da Universidade Federal de Minas Gerais (UFMG), organizou um dossiê precursor sobre o assunto no ano de 2014 (v. 24, n. 2), o qual foi coordenado pelos pesquisadores Elisa Maria Amorim, Gonzalo Leiva e Márcia Arbex. Os dois primeiros estão presentes neste dossiê.

O conjunto de textos aqui selecionados reúne tanto pesquisadores com trajetória de investigação e publicação na área de Literatura e Fotografia, como jovens pesquisadores que se debruçaram sobre o tema para produzir seus artigos, dissertações e teses. 0 que é um indício não só do crescente interesse sobre o diálogo entre o texto e a imagem, mas também o sinal de um reconhecimento acadêmico e, quiçá, de uma institucionalização de uma área de pesquisa específica no contexto das linhas de pesquisa de Literatura Comparada no Brasil.

Procurou-se, aqui, alinhar o material reunido no dossiê em quatro eixos principais, com a finalidade de facilitar a consulta e a compreensão da abordagem utilizada pelos autores dos trabalhos. São eles: Narrativas Hibridas - diálogos entre o texto e a imagem; Poesia e Fotografia; Ficção, Imagem e Testemunho: o eu e o outro; e, por último, Literatura Expandida.

Na seção Narrativas Hibridas - diálogos entre texto e imagem, os artigos analisam obras que dão ênfase ao caráter visual da literatura, com destaque para as relações das personagens e da trama "com" e "a partir" da fotografia. Esse eixo agrega obras cuja autoria ultrapassa a elaboração e a organização somente do texto escrito, bem como o plano tradicionalmente literário e narrativo, com o intuito de contemplar a criação artística de um modo plural, em uma poética interartística.

Abrindo esse primeiro eixo temático, Maria Cristina Baranlloni Lagos, em "Fotografía y representación em la novela El mapa y el território de Michel Houellebecq", discute as variadas temáticas que emergem da inter-relação entre a fotografia e a sua representação literária dentro da obra do escritor francês Michel Houellebecq. Para isso, Lagos divide a sua análise em quatro momentos: primeiramente, ela aponta a relação entre os diferentes tipos de representações visuais que estão expressos no texto. Em seguida, analisa criticamente as fotografias presentes na obra, logo depois compreende os mapas da protagonista da obra e, por fim, estabelece conexões entre a morte, o mapa e a fotografia.

Em "Sobre fotografia e condensação: a coleção 'lo mínimo”, Fernando Cury de Tacca discute a coleção de fotolivros "lo mínimo" e desenvolve questões relativas à relação entre o texto e a imagem em formatos pequenos. 0 trabalho de Tacca visa à compreensão da importância dessa coleção e a insere como parte da história do fotolivro. 0 ensaio "Entre documento e ficção: fotorrelatos na Espanha da década de 1960", de autoria de Elisa Maria Amorim Vieira, traz uma reflexão sobre o ressurgimento do gênero costumbrista. 0 corpus utilizado no estudo é composto pelo fotolivro Nuevas escenas matritenses e textos de Camilo José Cela.

Lúcio Flávio Gondim da Silva, em "A imagem da palavra e a palavra da imagem: o conto fotoliterário de Tércia Montenegro", analisa o posicionamento da autora ao se debruçar sobre o caráter visual da literatura, dando ênfase especial à relação que as personagens possuem com a fotografia. Consoante Silva, é possível verificar que, na produção de Montenegro, ocorre uma espécie de escrita fotográfica, na qual corpos em seus desejos são apresentados de modo pictórico, mas sem apresentar um caráter naturalista ou mesmo a perda do seu potencial lírico. Em "Poéticas interartísticas: nos limiares da criação literária”, de Fernanda Borges, o leitor é convidado a examinar obras compostas por artigos de jornal, desenhos, fotografias e mapas que ultrapassam a concepção tradicional do que se entende como romance. Borges discorre sobre as chamadas narrativas híbridas e interartísticas, com o intuito de refletir acerca de um movimento plural e heterogêneo.

Caroline Aparecida dos Santos Fernandes, por seu turno, direciona o seu olhar à obra Quando meu pai se encontrou com o ET fazia um dia quente (2011), de Lourenço Mutarelli. Com base na narrativa em questão, Fernandes busca 
verificar como se dá a construção da imagem paterna no desenvolvimento da obra, assim como analisar como essa personagem evoca o processo essencial da temporalidade da imagem. Já no ensaio de Luiz Carlos Girão, a problematização acerca da escolha da fotografia como elemento constitutivo e potencial da narrativa pictórica Alice in Wonderland, de Suzy Lee, é o que rege o seu estudo. Ao longo do texto "A fotografia como imagem-ficção em Alice in Wonderland, de Suzy Lee", Girão sublinha o processo de ficcionalização imagético, bem como o reposicionamento sensível do olhar proposto por Lee em sua obra.

Juliana Estanislau de Ataíde Mantonavi, em "Ilustração e complementariedade fotoliterária: o caso de Nadja, de André Breton", envereda pelo estudo da descrição e da análise das relações fotoliterárias presentes na referida obra, bem como os efeitos dos sentidos gerados no todo do livro. Além disso, Mantonavi visa a refletir sobre o potencial conotativo da fotografia e a compreender as interações e as interferências estabelecidas entre o texto e a imagem. Já em "Rememoração da ditadura por meio da fotografia: possíveis representações e leituras de P14311", Airton Pott adentra o passado obscuro da ditadura militar brasileira apresentada no livro de Diego Di Niglio. 0 autor analisa criticamente algumas fotografias da obra e discorre sobre a importância dessas imagens na narrativa.

Daniel Moutinho Souza, em "Uso da fotografia em Nove Noites, de Bernardo Carvalho, e Vou lá visitar pastores, de Ruy Duarte de Carvalho", fecha esse bloco de artigos. 0 autor apresenta uma leitura sobre as formulações teóricas clássicas relacionadas à fotografia. Em seguida, estuda comparativamente o uso das fotos nas duas obras

Passando, agora, para a seção Poesia e Fotografia, foram inseridos artigos em que a fotografia encarna, como afirma Adolfo Montejo Navas (2017), as vicissitudes do modernismo, mas também a sua crise de valores na pós-modernidade (aura, autoria, autonomia), em diálogo com a poesia que, desde o início do século XX, tem depurado seu campo de ação, buscando assim outra lateralidade do sentido: alteridade, diferença, outro porvir, outro "entre" na relação linguagem-mundo.

"Retrato de família em preto e branco" é o título do estudo em que Ana Claudia Costa dos Santos relata o processo de elaboração de um poema de sua autoria. Santos discute as relações do seu trabalho literário com a passagem do tempo, a epifania e a fotografia. Em "Escrever-se, fotografar-se: convergências entre Vivian Maier e Ana Cristina Cesar", Julia Pasinato Izumino lança uma luz sobre as convergências e divergências mapeáveis entre os autorretratos fotográficos da escritora estadunidense e a poesia mista de prosa, diário e correspondência íntima da artista brasileira. 0 foco de Izumino centra-se nos procedimentos de construção do sujeito ficcional trabalhados dentro dos gêneros autobiográficos e autorrepresentativos.

Ao analisar quatro poemas de Carlos Drummond de Andrade em "Retratos profanos: uma análise sobre morte e fotografia na poesia de Carlos Drummond de Andrade", Mariane Pereira Rocha e Aulus Mandagará Martins objetivam identificar as funções que a fotografia desempenha na relação que o eu-lírico drummondiano estabelece com a morte nos poemas selecionados para a análise, sendo eles: "Os mortos", "Os mortos de sobrecasaca", "Os rostos imóveis" e "Necrológico dos desiludidos do amor". Refere-se também à poesia o estudo seguinte de autoria de Patrícia Dauhali Clemente Guimarães, "Poesia e fotografia: um caminho para o letramento literário". A autora focaliza as potencialidades poéticas da fotografia e da escrita na educação, mais precisamente nas práticas pedagógicas na disciplina de Língua Portuguesa com estudantes do Ensino Fundamental.

Os textos que compõem o eixo Ficção, Imagem e Testemunho: o eu e o outro, abordam obras que buscam, no diálogo imagem e texto, especialmente na fotografia, enfrentar os limites da narrativa para elaborar a memória e testemunhar o trauma da experiência social e individual de catástrofes como a Shoa, as ditaduras militares latino-americanas e a submissão dos povos originários da América. No limiar entre "ser e não ser, entre sensível e inteligível, entre palavra e coisa, não é o abismo incolor do nada, mas a espiral luminosa do possível" (AGAMBEN, 2015, p. 32).

O ensaio de autoria de Jaime Edgardo Flores Chável e Daniel Carter abre essa terceira parte do dossiê. Em "La South American Misionary Magazin, 1893-1903. El discurso escrito y fotográfico anglicano em la construción de los indígenas de la Araucanía", os autores exploram o diálogo que se reverbera entre o texto e a fotografia na divulgação da ação missioneira anglicana na América do Sul na Revista South America Misionery Magazin. Já Hurí Elisabeth Tornay desenvolve um estudo acerca do período da ditadura militar em solo argentino. Em "Agencias que importan. Um conjunto fotográfico (im)pertinente", Tornay apresenta um conjunto de fotografias publicadas por dois jornais, bem como entrevistas com alguns dos fotógrafos e jornalistas que enfrentaram as variadas opressões durante o período ditatorial argentino. 
Os horrores praticados durante a II Guerra Mundial são elementos centrais do estudo de Lóren Cristine Ferreira Cuadros. No ensaio "Fotografia e arte abstrata: cruzamentos entre registro, ficção e testemunho em Gerhard Richter", a autora possui o objetivo de defender que, embora não correspondam ao testemunho em primeira mão dos registros fotográficos, as telas pintadas por Richter podem causar igual inquietação no seu espectador.

No quarto e último eixo temático do dossiê, Literatura Expandida, os artigos apresentam narrativas que incorporam outras manifestações artísticas, permitindo, assim, que elas sejam denominadas como narrativas híbridas e interartísticas. Tais textos exprimem preocupações para além das concepções modernistas da especificidade das linguagens artísticas, exprimindo-se em fotolivros e em outros meios de difícil definição.

David William Foster, em "Unhiding hidden urban madness: the asylum photographs of Claudio Edinger", procura analisar as estratégias utilizadas pelo fotógrafo brasileiro Claudio Edinger ao fotografar os pacientes de um manicômio localizado no estado de São Paulo, Brasil. "Poemas fotográficos de Magela Ferrero: resistencias de la imagen y la escritura en Personas que tienen hambre (2011)", de autoria de María Fernanda Piderit, aborda a obra da artista uruguaia Magela Ferreiro a partir de um ponto de vista originário da Literatura. André Magri Ribeiro de Melo fundamenta-se no diálogo entre diferentes artes para o desenvolvimento do seu estudo. Em "Imagens de quem escreve: entrenotas sobre o lugar do escritor", Melo discute alguns aspectos da relação entre a imagem e a palavra na obra fotobiográfica O lugar do escritor, do fotógrafo Eder Chiodetto. Seu estudo realça a impureza e a efemeridade como aspectos basilares da obra em questão.

0 texto "Didi-Huberman e a escrita: ensaiar o ver entre a imagem e o conceito", de Tatiane França Rangel, propõe uma leitura crítica de dois livros do filósofo e historiador francês, procurando mostrar como o estudioso elabora e defende o seu conceito de imagem enquanto potência dialética e força histórica. Dagmar Jana Bachraty fecha esse bloco de ensaios com o trabalho intitulado "La experiencia estética de la mirada: el ver y oír em la conformación de la palavra tejida em la obra Quipu Mapocho de Cecilia Vicuña”. A autora busca discutir a existência de uma linguagem visual como uma forma de recuperação e de uma comunicação ancestral no mundo da arte. Quipo Mapocho, obra da artista chilena Cecilia Vicuña, é o seu objeto de estudo.
Assim configurado, a presente edição da revista Letrônica, a qual é o resultado do trabalho intelectual de professores pesquisadores e de estudantes de pós-graduação de variadas instituições de ensino, visa a atingir o máximo de interessados, dada a crescente importância e a presença de diferentes análises no meio acadêmico abordando as relações entre a Literatura e a Fotografia. Agradecemos a participação dos nossos colaboradores e esperamos que o dossiê seja uma fonte de investigação e estímulo para o desenvolvimento de novas pesquisas.

Desejamos a todos uma leitura proveitosa.

\section{Referências}

AGAMBEN, Giorgio. Bartleby, ou da contingência. Belo Horizonte: Autêntica, 2015.

ARMSTRONG, Nancy. Fiction in the age of photography: the legacy of British realism. Cambridge: Massachusetts, 1999.

BARTHES, Roland. A câmera clara. 2. ed. Tradução de Júlio Castañon Guimarães. Rio de Janeiro: Nova Fronteira, 2015

BELLATIN, Mario. Shiki Nagaoka: una nariz de ficción. Buenos Aires: Sudamericana, 2001. BRIZUELA, Natalia. Depois da fotografia: uma literatura fora de si. Rio de Janeiro: Rocco, 2014 BRUNET, François. Photography and literature. London: Reaktion Books, 2009.

CUNNINGHAM, David; FISHER, Andrew; MAYS, Sas (ed.). Photography and literature in the twentieth century. Cambridge: Cambridge Scholars Publishing, 2008.

EDWARDS, Paul. Soleil noir: photographie \& littérature des origines au surréalisme. Rennes: Preesses Universitaires de Rennes, 2008.

LAMBRECHTS, Erich; SALU, Luc (ed.). Photography and literature: an international bibliography of monographs. London: Mansell, 1992.

LOUVEL, Liliane (dir). Texte/image: images à lire, textes à voir. Rennes: PUR, 2002. https:// doi.org/10.4000/books.pur.40820

LOUVEL, Liliane (dir.). Texte/image: nouveaux problèmes. Rennes: Presses Universitaires de Rennes, 2005. 
MONTEJO NAVAS, Adolfo. Fotografia \& poesia (afinidades eletivas). São Paulo: Ubu, 2017.

MONTIER, Jean-Pierre et al. (dir.). Littérature et photographie. Rennes: Presses Universitaires de Rennes, 2008.

MONTIER, Jean-Pierre. Avant-propos. In: MONTIER, Jean-Pierre et al. (dir.). Littérature et photographie. Rennes: Presses Universitaires de Rennes, 2008. p. 7-14.

ORTEL, Philippe (ed.). La littérature à l'ère de la photographie: enquête sur une révolution invisible. Paris: Chambon, 2002.

SOULAGES, François. Estética da fotografia: perda e permanência. São Paulo: Senac, 2010.

THELOT, Jérôme. Les inventions littéraires de la photographie. Paris: PUF, 2004.

RUSSEK, Dan. Textual exposures: photography in twentieth century Latin American narrative fiction (Latin American and Caribbean Studies). Calgay: University of Calgary Press, 2015. https://doi.org/10.2307/j.ctv6cfrst

VIERA, Elisa Amorim; QUIJADA, Gonzalo Leiva; ARBEX, Márcia. Apresentação ALETRIA: Revista de Estudos de Literatura, Belo Horioznte. Dossiê Literatura e Fotografia, v. 24, n. 2, p. 9-10, 2014. 